\title{
The Development of Perspective Taking: Understanding Differences in Information and Weighting
}

\author{
James A. Dixon and Colleen F. Moore
}

University of Wisconsin-Madison

\begin{abstract}
Dixon, James A., and MoORE, Colleen F. The Development of Perspective Taking: Understanding Differences in Information and Weighting. CHILD DEVELOPMENT, 1990, 61, 1502-1513. 2 separate aspects of perspective taking are that judgments attributed to another should depend on the information available to the other (Information effect) and on how the other's use of information differs from one's own (Weighting effect). These 2 aspects of perspective taking were studied in a moral judgment task with preschoolers, and second and fifth graders. Subjects were read a series of stories about a little boy transgressing and asked to make judgments from both their own perspective and that of a mother character in the stories. The mother story character had either the same information as the subject or only partial information. Valence of intention and consequence and the amount of mother's knowledge varied factorially. Subjects were clustered using scores derived from the judgments. 3 clusters were found that showed different levels of perspective-taking ability. There was a developmental progression in the 3 levels of perspective taking. Subjects in the Harshness cluster attributed harsher judgments to the mother perspective. Subjects in the Weighting cluster weighted information differently depending on the perspective from which they judged. Subjects in the Information-and-Weighting cluster weighted information differently depending on perspective, and also considered the amount of information available to the mother character in attributing judgments. The findings are compared to current theory on the development of perspective taking. Future research and theory need to consider the influence of both information and weighting differences on performance in perspective-taking tasks.
\end{abstract}

Perspective taking has been the focus of much attention because of its role in social development. It has been suggested that perspective taking is important in social interactions because it facilitates the anticipation of other people's thoughts. By anticipating another's thoughts, social interactions become more predictable and each party is allowed to plan actions with inferred knowledge of the other (Kelly, 1955). Perspective taking has been defined in various ways by different researchers, although most agree that it involves the ability to infer the cognitions of another person from previous and/or immediate information. Research has shown that perspective taking develops over middle childhood, from the age of 6 or 7 years, although some claim that perspective taking occurs in 3- or 4-yearolds (Costanzo, Coie, Grumet, \& Farnill, 1973; Feffer \& Gourevitch, 1960; Flavell, Botkin, Fry, Wright, \& Jarvis, 1968; Newman, 1986).
Perspective taking can be seen in two situations-when the subject and the other person have different information, and when the subject and the other person have the same information but combine it differently in formulating their judgments. The first situation, in which information is different, characterizes most perspective-taking tasks. The subject is presented with all relevant information and then asked to make a judgment from the perspective of another person who has only partial information. Perspective taking is shown if the subject successfully ignores the information not available to the other person's perspective. Developmental research on perspective taking has concentrated on situations in which information differs.

The second situation, in which information is identical but the subject and the other person interpret it differently, has not been considered separately in developmental re-

This research was supported in part by a grant to the second author from the Graduate School, University of Wisconsin-Madison. The authors appreciate the cooperation of the participating children, schools, and teachers. We are grateful to Arthur M. Glenberg, Janet Shibley Hyde, and James C. Mancuso for comments on an earlier version of the manuscript. Address correspondence to James A. Dixon, Department of Psychology, 1202 W. Johnson St., University of Wisconsin, Madison, WI 53706.

[Child Development, 1990, 61, 1502-1513. (C) 1990 by the Society for Research in Child Development, Inc. All rights reserved. 0009-3920/90/6105-0021\$01.00] 
search. Perspective taking based on differences in interpretation is also a pervasive part of everyday life. For example, when looking for an apartment, one roommate might be very concerned about location, while the other roommate might be more concerned with price. Both parties have the same information available, but they differ in how they weight aspects of it. A task used by Saltzstein et al. (1987) also illustrates this type of perspective taking. They asked subjects to make a judgment from both their own perspective and that of a mother. Both subject and mother had the same information. Perspective taking would be shown by systematic differences between the subject's own judgments and those attributed to the mother. Although Saltzstein et al. were not interested in perspective taking, their measure could assess perspective taking based on different weighting of identical information.

The goal of our study was to examine the development of these two types of perspective-taking ability: (a) perspective taking based on differences in the information available to two people, and (b) perspective taking based on differences in weighting the same information. We used a moral judgment task similar to that of Costanzo et al. (1973). The moral judgments of children can be represented by a weighted averaging model with developmental changes in the weights of intentions and consequences (Anderson, 1980; Leon, 1980, 1984; Surber, 1977, 1982). In the present study, subjects rated the actions of a little boy in a story from both the subject's own perspective and the perspective of the story boy's mother. The amount of information available to the mother story character varied. Sometimes the story mother knew both the boy's intention and the consequience, and sometimes she knew only the intention or only the consequence.

With this experimental design, the two aspects of perspective taking can be separated. First, we assessed perspective taking by comparing the judgments attributed to the mother story character when the mother knows a different amount of information. If the subject does perspective-take, then his or her judgments from the mother character's perspective should change depending on the information available to the mother. For ex- ample, the judgments attributed to the mother when consequence information is not available to her should show a smaller effect of consequence than judgments made when consequence information is available. We call these Information effects.

The second aspect of perspective taking was assessed by examining the nature of the differences in judgments when the subject and the mother had the same information. For example, assume that both the subject and the mother story character know both intention and consequence information. If the subject weights intention information more heavily than consequences in his or her own perspective but weights consequence more heavily than intentions in judging from the mother's perspective, then we have evidence of perspective taking. We call such differences as a function of perspective Weighting effects. ${ }^{1}$ Perspective taking has not been systematically examined in terms of these separate aspects, although Selman and Byrne (1974) include both information and weighting type effects in their theoretical model.

Based on past research showing good perspective taking by about age 8 (Feffer \& Gourevitch, 1960; Flavell et al., 1968; Newman, 1986; Selman \& Byrne, 1974), we expected that the second graders and fifth graders in our study would show perspective taking in terms of both Information and Weighting effects. When the information available to the mother character and the subject were different, we expected to see a decrease in the effect of the unknown information. When the information available to both the subject and the mother character was the same, we expected the second and fifth graders to stress intention information more and consequence information less in their own judgments as compared to judgments attributed to the mother character. For the preschoolers it is more difficult to make predictions. Past research has been mixed in demonstrating perspective taking with preschool children. However, because our method separates the effects of information and weighting on perspective taking, our study should provide new insight into the perspective-taking abilities of preschoolers and the developmental trends in the two separate aspects of perspective taking.

\footnotetext{
${ }^{1}$ Strictly speaking, the design of the present study does not allow separation of weight and scale value. According to the weighted averaging model, the net effect of a variable is the product of its weight times the range of the scale values. For simplicity, in the present study, we use the term "weighting" to refer to the net effects of intentions and consequences.
} 


\section{Child Development}

\section{Method}

\section{Subjects}

Seventeen preschoolers (mean CA = 5-1) from local day-care centers, 15 second graders (mean CA $=7-11$ ), and 16 fifth graders (mean $C A=10-4$ ) from a parochial school and a public school participated as subjects. Parental consent was obtained for all subjects. Four preschoolers were dropped from the study. Two could not use the response scale. Two did not attend to the task. The preschoolers were children who had missed the deadline for kindergarten by a small margin.

\section{Materials and Design}

The stimuli consisted of 23 short stories and accompanying drawings. The stories each described a mother and her son, a little boy, who emptied out his toy box. Past research has demonstrated the effectiveness of very similar stories with similar age groups (Costanzo et al., 1973; Surber, 1977, 1982). The 18 stories in the main design were constructed from a 3 (the valence of both the boy's intention) $\times 2$ (consequence of his action) $\times 3$ (mother's knowledge of the intention and consequence) factorial design. In the remaining five stories, both the subject and the mother story character knew only one type of information. These five stories were used to test the weighted averaging model and will not be discussed further.

The boy's intentions for emptying out the toy box were either good (cleaning his room), neutral (curiosity), or bad (intentionally making a mess). The consequences of his action were either good (finding some money) or bad (breaking a lamp). In all 18 of the stories in the main design, the subject knew both intention and consequence. In six of those 18 stories, the story mother had intention information only (Mother Doesn't Know Consequence condition), in six she had consequence information only (Mother Doesn't Know Intention condition), and in the remaining six she had both intention and consequence information (Mother Knows All condition).

Eight simple color drawings on $22.5 \times$ $30-\mathrm{cm}$ cards corresponded to story components for intention, consequence, mother's knowledge of intention, and mother's having knowledge of consequence. The story components are presented in the Appendix.

The rating scale consisted of nine schematic faces ranging from $3.5 \mathrm{~cm}$ to $6.5 \mathrm{~cm}$ in diameter. Four of the faces were smiling, four were frowning, and the center face was neutral. The faces increased in size from the center so that the largest of each type of face was on either end. The largest smiling and frowning faces were labeled "very good" and "very bad" by the experimenter. The neutral smiling face was labeled "neither good nor bad."

\section{Procedure}

The experiment was conducted in individual sessions lasting approximately $25 \mathrm{~min}$. The experimenter read a set of instructions to the subject that described the stories and the rating scale and included the two questions asked for each story. The instructions also contained a set of questions the experimenter used to verify that the subject understood the rating scale. The experimenter did not proceed until convinced that the subject understood the scale.

Two practice trials each containing one story and set of questions followed the instructions. One practice story contained positive consequence and positive intention known by both the subject and the mother story character. The other story contained negative consequence and negative intention also known by both mother and subject. The experimenter read each practice story, explained the pictures that accompanied the story, and asked, "How good or bad do you think the little boy in the story is?" and "How good or bad do you think the little boy's mother thinks he is?" The subject responded using the scale. The experimenter then asked the subject to give a verbal response and checked to see that it matched the response given on the scale.

The experimenter then read each story to the subject in one of four random orders and asked the two questions following each one. The order of the questions remained constant: own judgment, attributed judgment. The questions were presented in a constant order to make the subject's own view salient before asking for the other perspective. The subject, therefore, had to differentiate his or her own perspective from the mother's perspective.

\section{Results}

Initial analyses by grade showed effects replicating those of previous research. The preschoolers performed rather poorly on the task and showed little evidence of perspective taking. The second and fifth graders showed perspective-taking ability, but the 
second graders' ability looked less stable. While these results were as predicted, examination of the individual data patterns suggested the need for a more complex description. Within each age group there was considerable variability in response patterns, and these individual differences were obscured in the age group analysis.

The problems with averaging individual response patterns across groups have been discussed by Moore, Dixon, Haines, and Ahl (1989), Reed and Evans (1987), Siegler (1987), and others. Wilkening and Anderson (1982) have discussed the issue with regard to the information-integration approach. Wilkening and Anderson pointed out that averaging response patterns assumes that the subjects use the same or similar strategies to produce their responses. From the individual differences in the present data, it appeared that subjects within age groups may have done the task in very different ways.

In order to separate the subjects according to the individual differences in their response patterns, we clustered them on derived scores. We developed two sets of scores: Information scores and Weighting scores. The Consequence Information score measured the effect of the mother character having consequence information available in one condition and not having it in the other. The Consequence Information score was the difference between the slope of consequence in the Mother Doesn't Know Consequence condition and in the Mother Doesn't Know Intention condition. Since the effect of consequence should be very small in the Mother Doesn't Know Consequence condition and large in the Mother Doesn't Know Intention condition, the Consequence Information score should be greater than zero.

The Intention Information score was the difference between the slope of intention in the two knowledge conditions. To the extent that the child takes the mother's perspective, the effect of intention should be very small in the Mother Doesn't Know Intention condition because the mother story character is depicted as not having information about the little boy's intention. In the Mother Doesn't
Know Consequence condition, the effect of intention should be large since it is the only information presented. Therefore, the Intention Information score should also be greater than zero.

We based the Information scores on comparisons between attributed judgments under different information conditions so that the second measure of perspective taking, Weighting scores, would be independent of the first. Two Weighting scores were derived. The Intention Weighting score measured the effect of perspective on how intention information was weighted. The Intention Weighting score was the difference between the slope of intention from each perspective in the Mother Knows All (both perspectives have "all" information) condition. The slope of intention will differ between the own and attributed perspectives if the subject weights intention differently for the mother story character than for their own judgments. Since both subject and mother story character have both intention and consequence information, the difference between perspectives must come from differences in how the information is used. The Consequence Weighting score measured whether judging from the subject's perspective or the mother character's perspective would affect how consequence information was weighted. The Consequence Weighting score was the difference between the slope of consequence from the own and attributed judgments in the Mother Knows All condition.

Subjects were grouped via K-means clustering (Dixon, 1983) into three clusters after the In formation and Weighting scores were standardized by dividing by the variance. Three clusters were selected for analysis because clustering into two groups seemed inadequate to describe the individual differences and clustering into four groups did not provide any new information. ${ }^{2}$ The three clusters show three different levels of perspective taking. We have named the clusters descriptively according to their apparent perspective-taking ability. One cluster showed both Information and Weighting effects, a second showed only Weighting effects, and a

\footnotetext{
${ }^{2}$ Clustering into four groups separated four subjects from the cluster scoring well on both measures into a separate group. These four subjects differed from the others in their original cluster only in that their scores were larger. Since there were so few subjects in this group and the pattern of their scores did not differ from the other subjects, they were retained in the larger cluster. With a larger number of subjects, those that appear as outliers, such as the fourth cluster just described, might appear as members of other well-defined clusters.
} 


\section{Child Development}
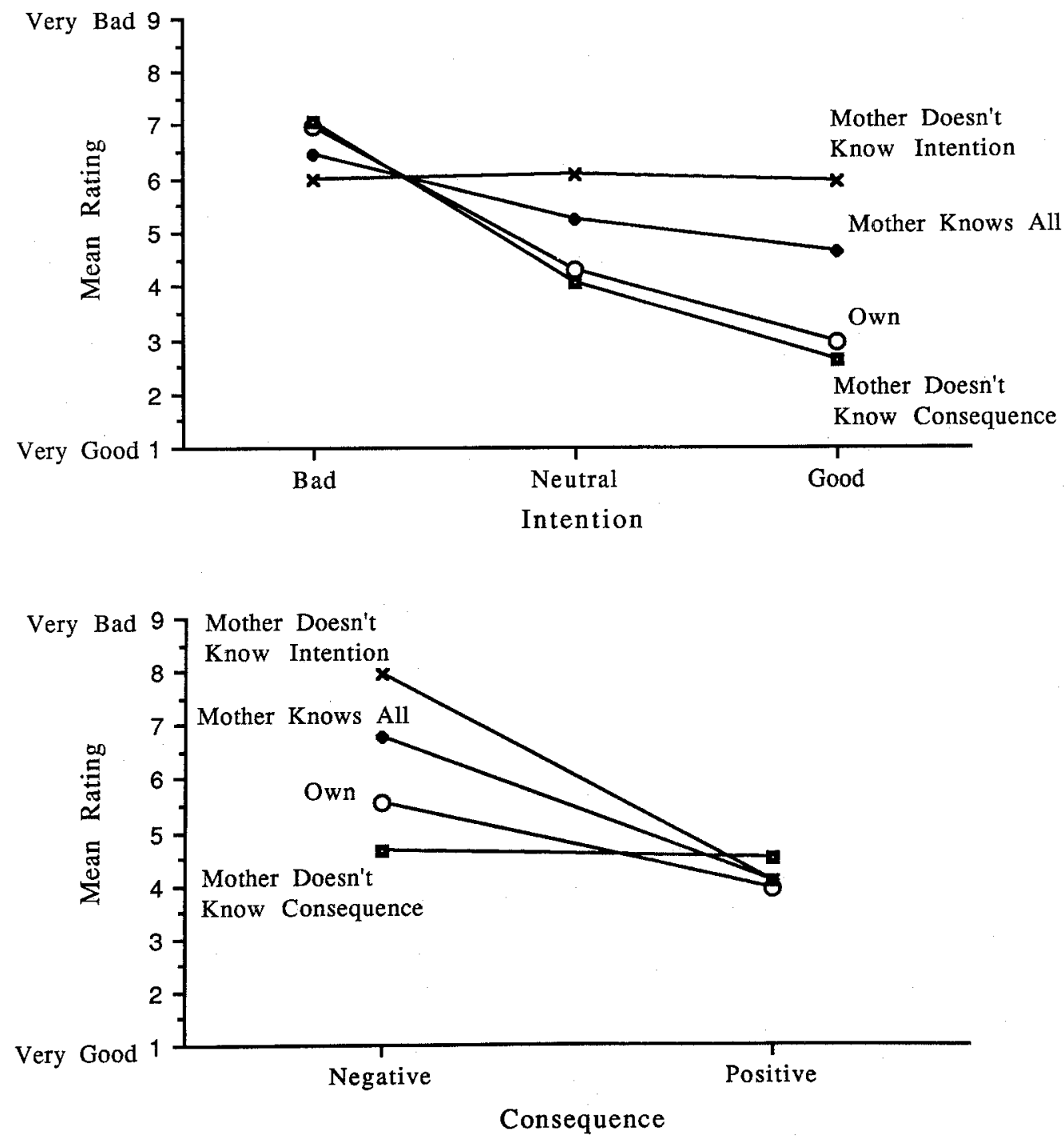

FIG. 1.-The upper panel shows mean attributed judgments for the Information and Weighting cluster as a function of intention, averaged over levels of consequence. The lower panel shows mean attributed judgments, averaged over levels of intention. Each level of mother knowledge-Mother Knows All, Mother Doesn't Know Consequence, and Mother Doesn't Know Intention-has a separate curve. The curve labeled Own is own judgments averaged over all levels of mother knowledge. One is the extreme good rating, 9 is the extreme bad rating, and 5 is neutral.

third showed evidence of perspective taking at only a very rudimentary level. ${ }^{3}$

\section{Information and Weighting Cluster}

The upper panel of Figure 1 shows the mean ratings of the 17 subjects in the Information and Weighting (IW) cluster averaged over consequence plotted as a function of in- tention. The lower panel of Figure 1 shows the mean ratings averaged over intention plotted as a function of consequence. The curves labeled Mother Knows All, Mother Doesn't Know Consequence, and Mother Doesn't Know Intention show the mean judgments from the attributed perspective under different knowledge conditions for the

${ }^{3}$ The mean Consequence Information score ranged from .54 to 3.75 across the three clusters. The mean Intention Information score ranged from -.76 to 2.33 . The mean Consequence Weighting score ranged from -.22 to 1.58 . The mean Intention Weighting score ranged from -.14 to .25 . 
mother story character. The curve labeled Own shows the mean judgments from the subject's own perspective averaged over all three mother knowledge conditions for ease of comparison.

An analysis of variance of the judgments from both perspectives showed two significant three-way interactions, ${ }^{4}$ perspective $x$ level of mother knowledge $x$ intention, $F(4,64)=8.95$, and perspective $\times$ level of mother knowledge $\times$ consequence, $F(2,32)$ $=27.70$. These interactions showed that the effects of both intention and consequence depended on the level of mother knowledge and perspective. Thus, both the information the mother story character received and the perspective the subject took had an effect on the judgments.

Information effects.-Subjects in the IW cluster were able to keep their own perspective (which had all information) separate from the mother's perspective. Strong evidence for perspective taking can be seen in the differences between the slopes in Figure 1. For example, in the upper panel the Mother Doesn't Know Intention curve is flat. This demonstrates that when the mother doesn't have intention information available it doesn't affect the judgments from that perspective. Similarly, in the lower panel the Mother Doesn't Know Consequence curve if flat.

The averaging model predicts that when one type of information is not presented, the relative weight of the remaining information and its slope should increase. Consistent with this prediction, in the upper panel the Mother Doesn't Know Consequence curve has a steeper slope than the Mother Knows All curve. In the lower panel, the Mother Doesn't Know Intention curve is steeper than the Mother Knows All curve. ${ }^{5}$ Thus, the subjects in the IW cluster show very sophisticated effects of amount of information.

Weighting effects.-Subjects in this cluster also showed perspective-taking ability by weighting information differently depending on which perspective they took. These subjects weighted intention information more heavily in their own judgments and consequence more heavily in their attributed judgments. The Own curve has a steeper slope than the Mother Knows All curve in the upper panel of Figure 1, showing the larger weight of intentions in judgments from the Own perspective. Conversely, in the lower panel the Mother Knows All curve has a steeper slope than the Own curve, showing the larger weight of consequences in judgments from the mother perspective.

Harshness effect.-Analysis of variance showed a main effect of perspective in the Mother Knows All condition, $F(1,16)=11.58$. The mean judgments from the mother and the own perspectives were 5.43 and 4.51 , respectively. This shows that these subjects systematically judged more harshly from the mother perspective.

\section{Weighting Cluster}

Information effects.-The judgments from the 11 subjects in the Weighting cluster did not show either of the three-way interactions indicative of information effects (perspective $\times$ level of mother knowledge $x$ intention, $F[4,40]=1.38, p>.25$, and perspective $\times$ level of mother knowledge $\times$ consequence, $F<1$ ). This indicated that the amount of information the mother story character received and the perspective the subject took had no significant effect on the judgments.

Weighting effect.-Subjects in the Weighting cluster weight intention heavily for their own judgments and weight it very lightly for the attributed perspective judgments. The perspective $x$ intention interaction was significant, $F(2,20)=29.79$. The upper panel of Figure 2 shows that Own judgments have a steep slope compared to the almost flat curves for attributed judgments. Further analyses showed that the difference was not a function of the information presented to the mother. When the own and attributed judgments from the All condition were entered into a separate analysis of variance, there was a significant perspective $\times$ intention interaction, $F(2,20)=11.68$. The perspective $\times$ consequence interaction was not significant, $F<1$. Thus, subjects in the Weighting cluster show perspective taking in their use of intention information but not consequence information.

Harshness effect.-When judgments from both perspectives from the Mother Knows All condition were entered into an analysis of variance the main effect of perspective was nonsignificant, $F<1$. Thus, the

${ }^{4}$ All significant $p$ 's $<.05$.

${ }^{5}$ Further tests that supported the weighted averaging model are not reported here since they do not bear directly on perspective taking. 


\section{Child Development}
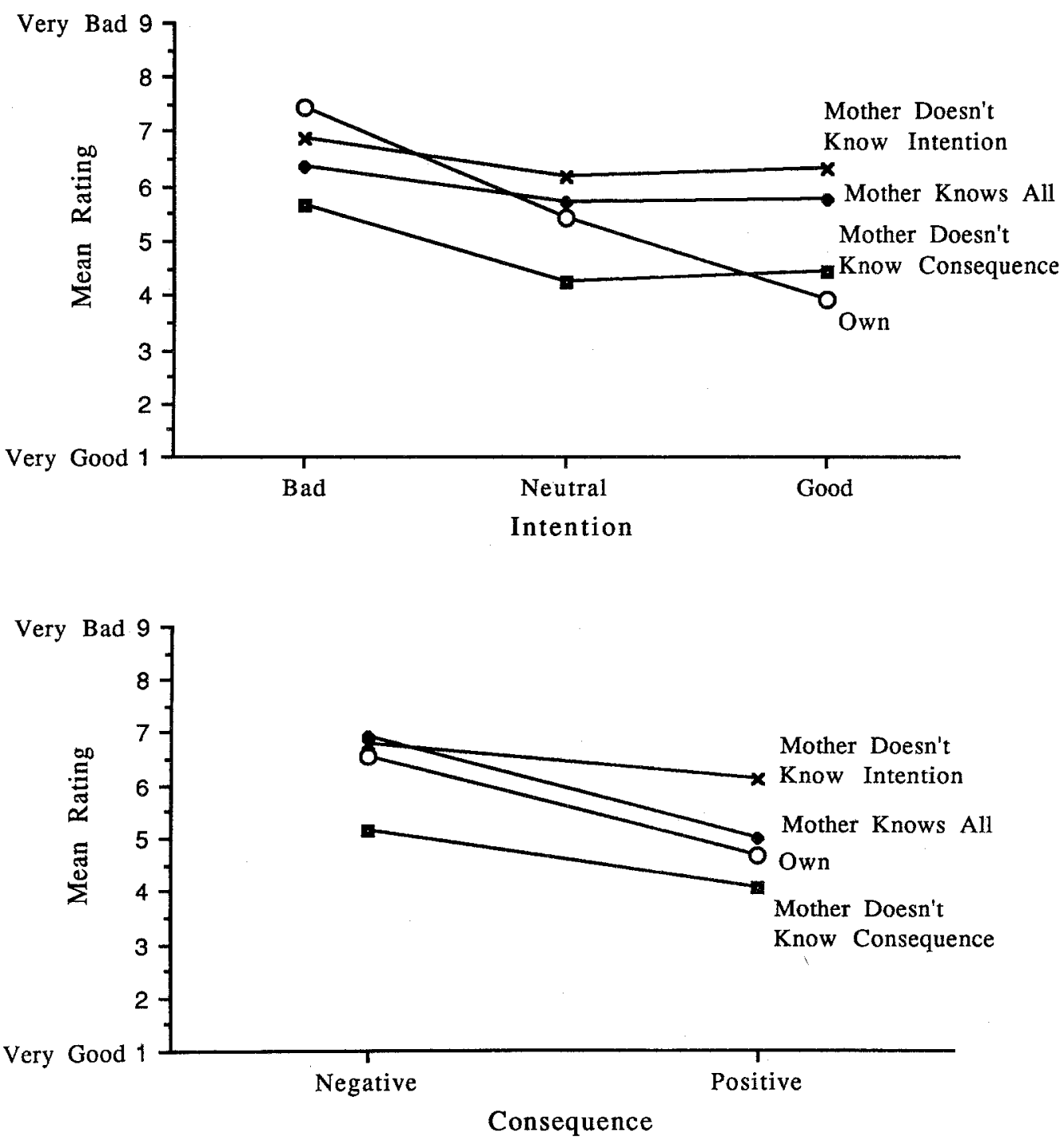

FIG. 2.-The upper panel shows mean attributed judgments for the Weighting cluster as a function of intention, averaged over levels of consequence. The lower panel shows mean attributed judgments, av. eraged over levels of intention. Each level of mother knowledge-Mother Knows All, Mother Doesn't Know Consequence, and Mother Doesn't Know Intention-has a separate curve. The curve labeled Own is own judgments averaged over all levels of mother knowledge. One is the extreme good rating, 9 is the extreme bad rating, and 5 is neutral.

subjects in the Weighting cluster did not show significant differences in how harsh their ratings were as a function of perspective.

\section{Harshness Cluster}

The mean judgments of the 20 subjects in the Harshness cluster are shown in Figure 3. The subjects in the Harshness cluster show little evidence of perspective-taking ability. Neither of the three-way interactions indicative of information effects on perspective taking were significant (perspective $\times$ level of mother knowledge $\times$ intention, $F<1$, and perspective $\times$ level of mother knowledge $\times$ consequence, $F[2,38]=1.21, p>.3$ ). Likewise, there were no significant differences between the slopes of the own and attributed curves in the Mother Knows All condition for either intention or consequence (interaction $F^{\prime}$ s $\left.<1\right)$. Thus, there were no weighting effects.

Although the predicted Information and Weighting effects are not significant, the Harshness effect might be interpreted as evidence of a small degree of perspective taking 

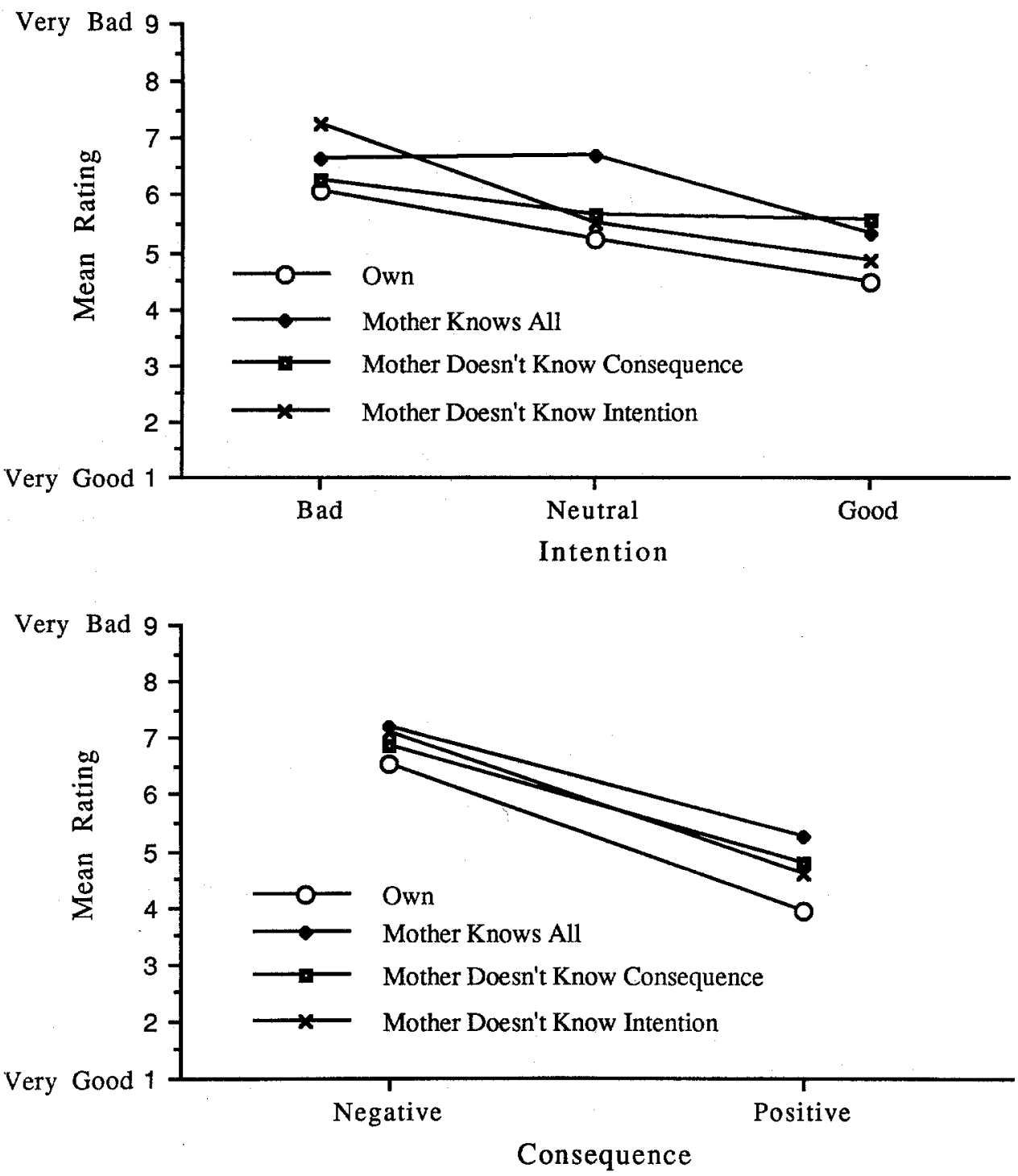

FIG. 3.-The upper panel shows mean attributed judgments for the Harshness cluster as a function of intention, averaged over levels of consequence. The lower panel shows mean attributed judgments, averaged over levels of intention. Each level of mother knowledge-Mother Knows All, Mother Doesn't Know Consequence, and Mother Doesn't Know Intention-has a separate curve. The curve labeled Own is own judgments averaged over all levels of mother knowledge. One is the extreme good rating, 9 is the extreme bad rating, and 5 is neutral.

for subjects in this cluster. There was a significant main effect of perspective for the Harshness cluster, $F(1,19)=19.12$. The subjects attributed harsher judgments to the mother story character (mean $=5.34$ ) than they made themselves (mean $=4.74$ ). This finding suggests that subjects in this cluster have a very rudimentary level of perspective taking in that they attribute harsher judg- ments to the mother character. These results may also be interpreted as the result of social categorization. Both interpretations are discussed below. ${ }^{6}$

\section{Validity of the Clusters}

The possibility exists that the cluster analysis found groups of random responders whose patterns of response are similar. This

${ }^{6}$ The weighted averaging model fit fairly well for the subjects in this cluster. This shows that these subjects were not a group of poor performers who did not understand the task. 
1510 Child Development

TABLE 1

Number (and Proportion of Subjects) in Each Grade in Each Cluster

\begin{tabular}{cccc}
\hline \hline & \multicolumn{3}{c}{ Cluster } \\
\cline { 2 - 4 } GradE & Harshness & Weighting & IW \\
\hline Preschool $\ldots \ldots \ldots \ldots \ldots$ & $12(.71)$ & $5(.29)$ & $0(0)$ \\
Second $\ldots \ldots \ldots \ldots \ldots$ & $4(.27)$ & $4(.27)$ & $7(.46)$ \\
Fifth $\ldots \ldots \ldots \ldots \ldots \ldots$ & $4(.25)$ & $2(.125)$ & $10(.625)$ \\
\hline
\end{tabular}

seems unlikely, given that the scores used to cluster the subjects were the differences between slopes so that only a very small part of the total data pattern was used in clustering. The differences between the clusters in the Harshness effect also add validity to the clustering solution because no information about absolute magnitude of the judgments was used in the clustering. Stronger evidence in support of the clustering solution comes from conditions not used to derive the clustering scores. The subjects made judgments from their own perspective at each level of mother knowledge. Only the own judgments from the All condition were used to derive the clustering scores. If the clustering program found random responders with similar patterns, there should not be significant differences between own judgments made concomitantly with the other two mother knowledge conditions. Analyses of variance of the own judgments from the Mother Doesn't Know Consequence and Mother Doesn't Know Intention conditions showed significant intention $x$ cluster interactions, $F(2,70)=7.62$, and $F(2,58)=4.24$, respectively. Examination of the means showed that both the IW and Weighting cluster had a greater effect of intentions in their own judgments than the Harshness cluster, as expected. When the IW and Weighting cluster were compared, there was a main effect of cluster, indicating that the IW cluster judged less harshly than the Weighting cluster, $F(1,26)=5.43$.

These tests offer rather strong support for the validity of the clustering solution. These own judgments are independent of the judgments used to derive the scores. Further, we would expect that unless the clustering were finding qualitative differences among the subjects, these own judgments should not systematically differ because they do not relate to perspective taking directly. The analysis shows that the clusters differ not only in per- spective-taking ability but also in how the subjects judge from their own perspective.

\section{Developmental Trends within Clusters}

The proportions of subjects in each grade falling into each cluster are shown in Table 1. A chi-square test of independence showed that the proportion of subjects in each cluster depended on grade, $\chi^{2}(4, N=48)=16.32$, $p<.01 .^{7}$ The progression through clusters clearly shows the development of perspective-taking ability. The largest proportion of preschoolers fell in the Harshness cluster. These subjects perspective-take at a very rudimentary level and have yet to acquire the more mature abilities of the other clusters. However, a fair number of preschoolers also fell in the Weighting cluster $(29 \%)$. These subjects, it will be recalled, show evidence of perspective taking on one of the Weighting measures. The subjects in this cluster appear to have a solid beginning at perspective taking that is yet to develop into the more mature ability of the IW cluster subjects.

The second graders differ dramatically from the preschoolers. Almost half of the second graders are in the IW cluster, which attests to their good perspective-taking ability. The remainder are split evenly between the Weighting and Harshness clusters. Clearly, the second-grade subjects are a fairly mixed group. While almost half perspective-take at a very mature level, about a quarter do so at an intermediate level, and the other quarter are at the least advanced level.

The majority of fifth graders fell in the IW cluster, with a very small proportion of them in the Weighting cluster. However, almost a quarter of them are still in the Harshness cluster. This is surprising because most fifth graders would be expected to have reasonably good perspective-taking ability. Whether these individuals would show social deficits in other areas is unknown.

${ }^{7}$ Delucchi (1983) cites a number of studies that show the robustness of the chi-square test with small expected frequencies such as ours. 


\section{Discussion}

The three clusters might be thought of as a sequence through which perspective-taking ability progresses (Moore et al., 1989). Each cluster shows a distinct level of perspectivetaking ability. The proportion of subjects from each grade in each cluster shows how perspective-taking ability develops crosssectionally with age. Of course, it would be ideal to study perspective taking longitudinally to verify the obtained developmental sequence. In a longitudinal study it would be possible to study not only the changes in cluster membership with time but also the rate at which changes in the Information and Weighting effects occur and whether they are saltatory or accumulative.

The results of the present study show that the development of perspective-taking ability progresses with age, but that there are also individual differences. Table 1 shows that within each grade subjects perform the task at different levels of ability. Averaging the responses of subjects within a grade would yield a pattern that does not really represent how any of them performed the task.

Selman and Byrne (1974) made a theoretical distinction similar to our distinction between Information and Weighting effects. At Level 1 of Selman and Byrne's developmental model the child understands that people in different situations or having different information may have different interpretations, what we have been referring to as the Information effect. At Level 2, the child also understands that people may think or feel differently because they have different ideas or values. This is what we have been referring to as the Weighting effect. At Level 3, the child can take the perspective of a third person and view the situation from outside the views of the involved parties. ${ }^{8}$ Thus, according to Selman and Byrne's theory, understanding the Information effect should be developmentally prior to the Weighting effect. Our results stand in contrast to their model. We found that the Weighting effect was developmentally prior to the Information effect. The discrepancy between our results and those of Selman and Byrne's study may come from the measures as well as other factors. Selman and Byrne's measure involved presenting a story that did not depict any two characters as having the same information. Further, neither of the questions that were intended to assess perspective taking at Level 2 stated that two characters had the same information. This makes assessing the Weighting effect difficult because the perspectives differ in both information and in the values or beliefs of the characters. Therefore, the Weighting effect in Selman and Byrne's study may have been obscured by differences in the amount of information available.

The developmental priority of the Weighting effect conflicts with past conclusions of other researchers as well. Higgins (1981) summarized past research as having shown that "situational role taking" (where information is different between perspectives) is easier and developmentally prior to "individual role taking" (where differences are in terms of individual values). A number of factors may contribute to the discrepancy between Higgins's conclusion and our findings. First, it must be remembered that weighting different sources of information as a function of the perspective taken is not a logical requirement of most perspectivetaking tasks. For example, there is nothing inherent in our task that requires children to weight intention information more heavily in their own judgments as compared to the mother's. Therefore, the existence of the Weighting effect is likely only in situations where the alternative perspective has a welldefined value system different from the child's. We believe that our task facilitated detection of the Weighting effect because it used a mother story character and moral judgment. Detection of the Weighting effect should be best when the child has welldefined beliefs about how the other person would respond and believes the other will weight information differently. The second factor that may help account for the discrepancy concerns averaging of age group responses. If responses are being considered as an age group, then there must be good consistency in terms of what the children believe about the value system of the taken perspective. Otherwise, averaging over subjects will obscure the Weighting effect. Analyzing individual differences may therefore also facilitate detection of the Weighting effect.

The developmental ordering we observed seems to us to be more reasonable than that proposed in previous work. Consider first the Harshness effect. The Harshness effect appears to be an immature form of

${ }^{8}$ Selman and Bryne's model has two dimensions: distinguishing perspectives and relating perspectives. Our study addresses the distinguishing-perspectives dimension. 


\section{Child Development}

the Weighting effect. The children in the Harshness cluster distinguish their perspective from the mother perspective only on the basis of how harsh the judgments are. Young children may actually experience their parents' judgments as more harsh than their own. There are two possible interpretations of the Harshness effect. First, the Harshness effect may be the result of the children taking the perspective of the mother story character. Second, the Harshness effect may be the result of social categorization. Social categorization here refers to accessing some knowledge or rule about how a type of person behaves. This process does not involve perspective taking. Children would form judgments from their own perspective and then adjust that value by some amount in accord with a rule such as, "Mothers always judge more harshly."

Both of these interpretations suggest that the children in the Harshness cluster are aware that two people with the same information may have different opinions. This awareness seems a likely precursor to weighting information differently depending on perspective. Children may begin by becoming aware that different perspectives have potentially different interpretations of a situation (i.e., mothers judge more harshly). They may then begin to form distinct judgment strategies for people who reliably judge differently than they do. Finally, children may develop the ability to ignore information not presented to the other perspective. Only the last step requires what Piaget calls "decentering," in which one's own perspective is simultaneously contrasted with that of another.

The Harshness and Weighting effects also seem likely to precede the Information effect if one considers the type of perspectivetaking situations children are most likely to encounter. Situations in which both participants have the same information occur constantly. In many of these situations, children will certainly have different opinions from each other and from parents. Situations in which a child has more information than another and knows it probably occur with much less frequency. Therefore, it is not surprising that we see a very early awareness of weighting differences, but that only later are children able to use differences in the amount of information. Of course, another possibility is that the sequence of development of information and perspective knowledge depends on the specific social context in ways that are yet unexplored.
Our findings might also have implications for measuring deficits in social skill development. It would be interesting to know what other differences in social skills there might be between subjects in each of the clusters. For example, for subjects who are the same age, those in the Harshness cluster would be expected to be the least socially skilled, and those in the IW cluster would be expected to be the most skilled. Further, fifth graders in the Harshness cluster might be expected to have problems with their social skills because children of this age should be fairly well advanced in perspective taking. Research on peer relations has shown that aggressive children who are rejected by their peers are likely to show a negative bias in inferring the intentions of others (Dodge, 1980). It is interesting to note that in many studies of peer relations, approximately $10 \%-$ $25 \%$ of the total sample is identified as peer rejected and neglected (Coie, Dodge, \& Coppetelli, 1982; French, 1988). In the present study, approximately $20 \%$ of the second and fifth graders fell in the Harshness cluster. Those children falling in the Harshness cluster do not show understanding of the differences between people due to differences in their available information or differences in their perspectives. In addition, subjects in the Harshness cluster attribute harsher judgments to the other, a finding that is somewhat similar to the negative bias in attribution found by Dodge (1980). Whether children who are deficient in perspective-taking skills are at risk to be rejected by their peers needs to be studied more thoroughly.

In summary, the Information and Weighting effects both appear to be integral parts of the development of perspective taking. Most past research on the development of perspective taking has failed to examine both aspects of perspective taking because they are difficult to separate. By comparing own and attributed judgments, we have controlled for developmental changes in how the information is used from one's own perspective. The cluster analysis revealed that the development of perspective taking may occur at different rates for different individuals. Interestingly, age provided only a rough predictor, even for the fifth graders. This finding has implications for previously observed differences in the social abilities of children, especially those in the older age groups.

\section{Appendix}

\section{Intentions}

Good.-This little boy wanted to be helpful and clean up his room. He said to himself, "I'll 
empty my toy box onto the floor so that I can arrange it neatly."

Bad.-This little boy was feeling cross and wanted to mess up his room. He said to himself, "I'll empty my toy box onto the floor so that my room is real messy."

Neutral.-This little boy was curious about what was in his toy box. He said to himself, "IIl empty my tox box onto the floor so that I can see all my toys."

\section{Mother's Knowledge of Intention}

Has knowledge.-The boy's mother was standing right outside his door. He didn't know she was there. She heard every word he said.

Has no knowledge.-The boy's mother was in the next room and didn't hear what he said.

\section{Consequences}

Bad-As he emptied out the toy box, he knocked over a lamp and broke it.

Good-As he emptied out the toy box, he found some of his money that he had lost.

\section{Mother's Knowledge of Consequence}

Has knowledge.-Then his mother walked in and saw what had happened.

Has no knowledge.-His mother never knew what had happened.

Intentions only.-Then he emptied out his toy box and that's all we know about this story.

Consequences only.-This little boy was in his room. He walked over to his toy box and emptied it onto the floor.

\section{References}

Anderson, N. H. (1980). Information integration theory in developmental psychology. In F. Wilkening, J. Becker, \& T. Trabasso (Eds.), Information integration by children (pp. 1-45). Hillsdale, NJ: Erlbaum.

Coie, J. D., Dodge, K. A., \& Coppotelli, H. (1982). Dimensions and types of social status: A crossage perspective. Developmental Psychology, 18, 557-570.

Costanzo, P. R., Coie, J. D., Grumet, J. F., \& Farnill, D. (1973). A reexamination of the effects of intent and consequence on children's moral judgments. Child Development, 44, 154 161.

Delucchi, K. L. (1983). The use and misuse of chisquare: Lewis and Burke revisited. Psychological Bulletin, 94, 166-176.

Dixon, W. J. (1983). BMDP statistical software. Berkeley: University of California.

Dodge, K. A. (1980). Social cognition and children's aggressive behavior. Child Development, 54, 1386-1399.

Feffer, M. M., \& Gourevitch, V. (1960). Cognitive aspects of role taking in children. Journal of Personality, 28, 383-396.

Flavell, J. H., Botkin, P. I., Fry, C. L., Jr., Wright, J. W., \& Jarvis, P. E. (1968). The development of role taking and communication skills in children. New York: Wiley.

French, D. (1988). Heterogeneity of peer rejected boys: Aggressive and nonaggressive subtypes. Child Development, 59, 976-985.

Higgins, E. T. (1981). Role takng and social judgment: Alternative developmental perspectives and processes. In J. H. Flavell \& L. Ross (Eds.), Social cognitive development: Frontiers and possible futures (pp. 119-153). New York: Cambridge University Press.

Kelly, G. (1955). The psychology of personal constructs. New York: Norton.

Leon, M. (1980). Integration of intent and consequence information in children's moral judgments. In F. Wilkening, J. Becker, \& T. Trabasso (Eds.), Information integration by children (pp. 1-45). Hillsdale, N.J.: Erlbaum.

Leon, M. (1984). Rules mother and sons use to integrate intent and damage information in their moral judgments. Child Development, 55, 2106-2113.

Moore, C. F., Dixon, J. A., Haines, B. A., \& Ahl, V. (1989, May). A model of individual differences and developmental sequence in proportional reasoning: A theory of fuzzy stages. Paper presented at the meeting of Midwestern Psychological Association, Chicago.

Newman, D. (1986). The role of mutual knowledge in the development of perspective taking. $D e$ velopmental Review, 6, 122-145.

Reed, S. K., \& Evans, A. C. (1987). Learning functional relations: $A$ theoretical and instructional analysis. Journal of Experimental Psychology: General, 116, 106-108.

Saltzstein, H. D., Weiner, A. S., Monk, J. J., Supraner, A., Blank, R., \& Schwartz, R. P. (1987). Comparison between children's own moral judgments and those they attribute to adults. Merrill-Palmer Quarterly, 33, 33-5l.

Selman, R. L., \& Byrne, D. F. (1974). A structural developmental analysis of levels of role taking in middle childhood. Child Development, 45, 803-806.

Siegler, R. S. (1987). The perils of averaging data over strategies: An example from children's addition. Journal of Experimental Psychology: General, 116, 250-264.

Surber, C. F. (1977). Developmental processes in social inference: Analysis of intentions and consequences in moral judgments. Developmental Psychology, 13, 654-665.

Surber, C. F. (1982). Separable effects of motive, consequences, and presentation order on children's moral judgments. Developmental Psychology, 18, 257-266.

Wilkening, F., \& Anderson, N. H. (1982). Comparison of two rule assessment methodologies for studying cognitive development and knowledge structure. Psychological Bulletin, 92, 215-237. 
This document is a scanned copy of a printed document. No warranty is given about the accuracy of the copy. Users should refer to the original published version of the material. 